\title{
Precision treatment exploration of breast cancer based on heterogeneity analysis of IncRNAs at the single-cell level
}

Yan Zhang ${ }^{1+}$, Denan Zhang ${ }^{1 \dagger}$, Qingkang Meng ${ }^{1+}$, Ziqi Liü ${ }^{2+}$, Hongbo Xie $^{1}$, Lei Liu ${ }^{1}$, Fei Xu ${ }^{1}$ and Xiujie Chen ${ }^{{ }^{*}}$

\begin{abstract}
Background: Breast cancer (BC) is a complex disease with high heterogeneity, which often leads to great differences in treatment results. Current common molecular typing method is PAM50, which shows positive results for precision medicine; however, room for improvement still remains because of the different prognoses of subtypes. Therefore, in this article, we used IncRNAs, which are more tissue-specific and developmental stagespecific than other RNAs, as typing markers and combined single-cell expression profiles to retype BC, to provide a new method for BC classification and explore new precise therapeutic strategies based on this method.

Methods: Based on IncRNA expression profiles of 317 single cells from 11 BC patients, SC3 was used to retype BC, and differential expression analysis and enrichment analysis were performed to identify biological characteristics of new subtypes. The results were validated for survival analysis using data from TCGA. Then, the downstream regulatory genes of IncRNA markers of each subtype were searched by expression correlation analysis, and these genes were used as targets to screen therapeutic drugs, thus proposing new precision treatment strategies according to the different subtype compositions of patients.
\end{abstract}

Results: Seven IncRNA subtypes and their specific biological characteristics are obtained. Then, 57 targets and 210 drugs of 7 subtypes were acquired. New precision medicine strategies were proposed according to the different compositions of patient subtypes.

Conclusions: For patients with different subtype compositions, we propose a strategy to select different drugs for different patients, which means using drugs targeting multi subtype or combinations of drugs targeting a single subtype to simultaneously kill different cancer cells by personalized treatment, thus reducing the possibility of drug resistance and even recurrence.

Keywords: Precise treatment, Breast cancer, Heterogeneity analysis, Single cell sequencing, LncRNA

\footnotetext{
* Correspondence: chenxiujie@ems.hrbmu.edu.cn

†Y Yan Zhang, Denan Zhang, Qingkang Meng and Ziqi Liu contributed equally to this work.

${ }^{1}$ College of Bioinformatics Science and Technology, Harbin Medical

University, Harbin 150081, Heilongjiang Province, P. R. China

Full list of author information is available at the end of the article
}

(C) The Author(s). 2021 Open Access This article is licensed under a Creative Commons Attribution 4.0 International License, which permits use, sharing, adaptation, distribution and reproduction in any medium or format, as long as you give appropriate credit to the original author(s) and the source, provide a link to the Creative Commons licence, and indicate if changes were made. The images or other third party material in this article are included in the article's Creative Commons licence, unless indicated otherwise in a credit line to the material. If material is not included in the article's Creative Commons licence and your intended use is not permitted by statutory regulation or exceeds the permitted use, you will need to obtain permission directly from the copyright holder. To view a copy of this licence, visit http://creativecommons.org/licenses/by/4.0/ The Creative Commons Public Domain Dedication waiver (http://creativecommons.org/publicdomain/zero/1.0/) applies to the data made available in this article, unless otherwise stated in a credit line to the data. 


\section{Introduction}

Breast cancer (BC) is one of the most common causes of cancer-related deaths in women $[1,2]$. Chemotherapy is one of the chief means to treat $\mathrm{BC}$, but its clinical outcomes vary largely [3]. Studies have shown that the poor prognosis of $\mathrm{BC}$ is mainly because of intratumoral heterogeneity [4]. Accurate subtyping of $\mathrm{BC}$ can better analyze intratumoral heterogeneity, make tumor diagnosis more accurate, and make the prognostic difference of subtypes more significant. The treatment strategies explored based on precise classification can greatly improve the effect of treatment and reduce the chance of treatment failure and tumor recurrence.

Recently, commonly used subtyping strategies of BC have mostly been based on histological analysis, and multigene signatures provide biological insight and risk stratification in $\mathrm{BC}$ [5-8]. Among them, intrinsic molecular subtypes, defined by the mRNA expression of 50 genes (PAM50), including luminal A, luminal B, HER2-enriched, basal-like and normal-like, have been widely recognized and applied [9-11]. Treatment outcomes and prognoses of PAM50 subtypes are different [12-14]. Luminal A subtype has the best prognosis, while the prognosis of TNBC (triple-negative breast cancer) subtype is worst [15-17]. (In clinical research, TNBC is often used to approximately replace the basal-like subtype, as they overlap approximately by $80 \%[18,19])$. These studies suggest that subtyping methods based on histological multicell levels cannot reveal complete intratumoral heterogeneity. PAM50 subtypes reflect the average status of molecular characteristics of cells in the tissue. Some tumor cells may be resistant to drugs, resulting in cancer progression or even recurrence, which can explain the failure of chemotherapy to some extent.

In recent years, the development of single cell sequencing technology has provided a great opportunity to excavate intratumoral heterogeneity information of $\mathrm{BC}$ for precise treatment due to the following advantages: bulk sequencing technologies provide the average level of expression of genes distributed in multiple cells of tissue [20], and information on low-abundance genes and intratumoral heterogeneity will be lost [21, 22]. However, single-cell sequencing technologies can reveal the gene expression status of single cell, detect differences in genetic information between cells, and help to explain the mechanism of cancer progression [23, 24]. Therefore, the subtyping approaches based on single cells are better at revealing intratumoral heterogeneity than subtyping approaches based on multiple cells $[7,25]$.

However, the current classification of $\mathrm{BC}$ at the singlecell level mainly focuses on mRNAs/genes. Woosung Chung et al. used a single-cell gene expression profile to divide $11 \mathrm{BC}$ patients into ER+, HER2, and TNBC subtypes [26], but it was not much different from the
PAM50 subtypes. Although many contributions have been made to gain insight into the molecular characteristics of BC cells, room still remains for further study.

Increasing evidences show that lncRNAs play important roles in cell differentiation, migration and apoptosis by regulating gene expression patterns, and lncRNA expression is more tissue-specific, developmental-stage-specific and cell-type-specific than mRNA expression, suggesting that lncRNAs may become key regulators of cell fate and cell-type-specific functions [27-32]. Based on this, we suspect that lncRNAs can also be used for BC subtyping. Subtyping individual cells based on lncRNA expression profiles may be more conducive to revealing intratumoral heterogeneity and obtaining more accurate subtyping results with precise diagnosis and significant prognosis to further explore more effective treatment strategies.

Because subtyping methods of $\mathrm{BC}$ based on single-cell lncRNA sequencing data can show the molecular characteristics of single cells, we hypothesize that multiple subgroups/subtypes of cancer cells can be found in the same patient, which may lead to treatment failure or tumor recurrence. We should develop more accurate and effective clinical treatment measures based on the advantages of single-cell analysis. For patients with different subtypes, different drugs should be selected for treatment. These drugs can be targeted multi-subtype drugs or a combination of targeted single-subtype drugs to improve the medication efficiency and reduce the toxicity and side effects.

In this article, we combined single-cell sequencing data of BC and lncRNA expression profile to subtype 317 tumor cells from $11 \mathrm{BC}$ patients in order to more precisely discover single-cell subtypes and explore precise treatment strategies for patients with multiple subtypes (Fig. 1)

\section{Methods \\ Data processing}

Single cell expression profiles (GSE75688) of lncRNAs and PCGs (protein-coding genes) with processed TPM values in 517 cells of 13 samples from $11 \mathrm{BC}$ patients were downloaded from the GEO database [33]. These samples belong to four subtypes of PAM50 subtypes, including luminal A (BC01-BC02), luminal B (BC03), HER2-enriched (BC04-BC06), and basal-like/TNBC (BC07-BC11), while BC03LN and BC07LN collected from regional metastatic lymph nodes belong to luminal B and basal-like, respectively. Tumor cells, stromal cells, and tumor infiltrating immune cells were isolated by the label information of cells downloaded directly from the article of Chung W et.al [26]. The results of cell isolation showed that BC09 cells were all nontumor cells and were not included in the subsequent analysis.

We extracted the expression profiles of lncRNAs and PCGs according to gene type information (lncRNA: 


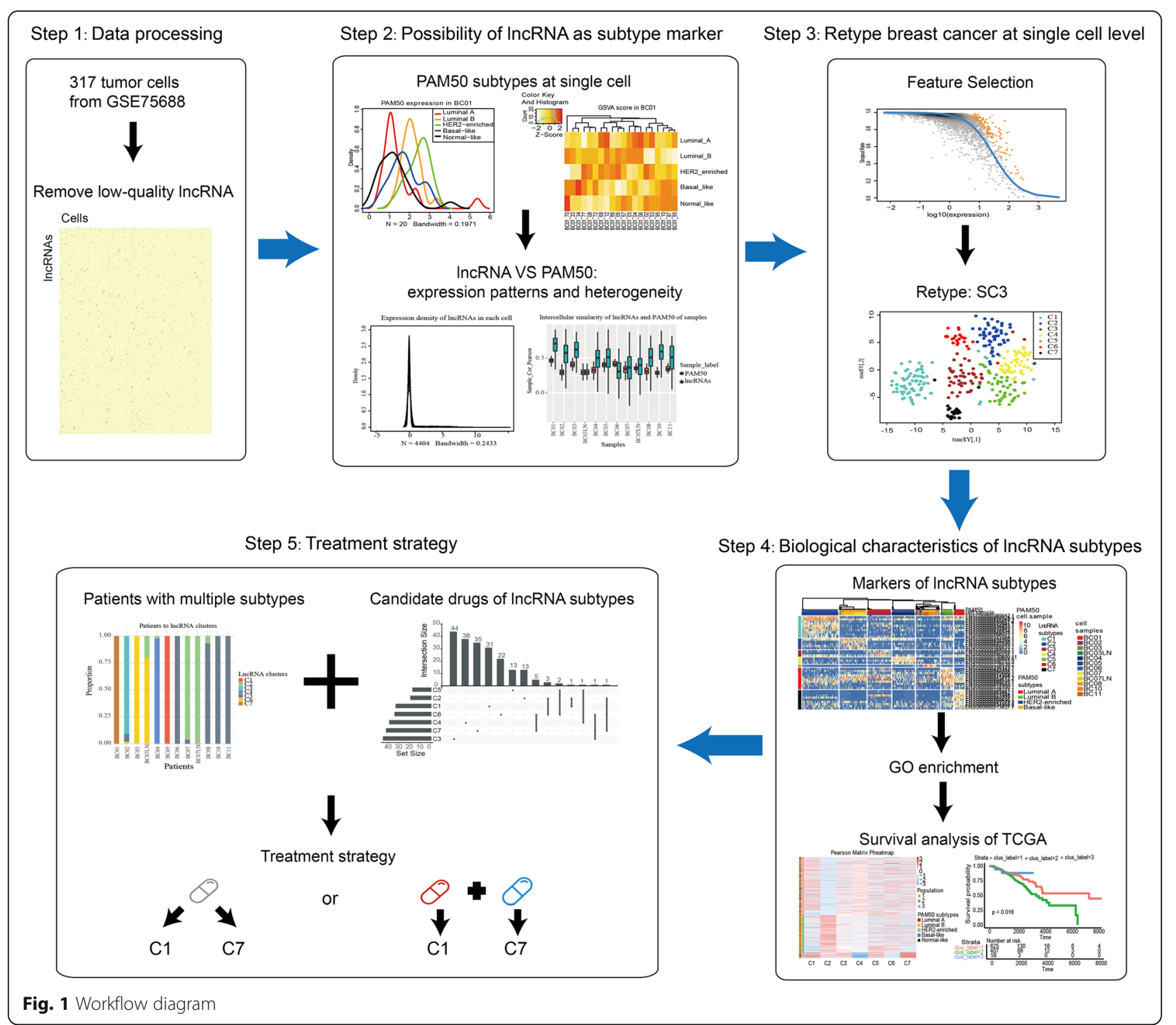

3prime overlapping ncRNA, antisense, lincRNA, processed transcript, sense intronic, sense overlapping; PCGs: protein coding genes) contained in GENCODE [34]. To remove lncRNAs or PCGs with low expression values, the following steps were applied: First, lncRNAs and PCGs with TPM values $<1$ in all tumor cells were considered unreliable and removed. Second, lncRNAs and PCGs expressed in $<1 \%$ of tumor cells were removed. Then, TPM values were $\log 2$-transformed after adding a value of one.

In all, 317 single tumor cells of 12 samples from 10 patients along with 4404 lncRNAs and 15,637 PCGs were applied for the downstream analysis.

\section{Intratumoral heterogeneity analysis}

To illustrate the intratumoral heterogeneity of $\mathrm{BC}$, we compared the similarity of IncRNA expression between cells. The R package Rtsne (version 0.15) [35] was used for the visualization of cell distances in the reduced 2D space of all mixed cells, tumor cells, and nontumor cells to represent the relative positions of the coordinates for comparing the degree of similarity between cells.

\section{Analysis of PAM50 subtypes at the single-cell level}

To show the molecular characteristics of PAM50 subtypes at single cell level, we took the following steps: 1 . The $\mathrm{R}$ package stats (version 4.0.3) [36] was used to obtain the expression density curves of PAM50 subtypes in 12 samples. The average expression value of signature genes of each PAM50 subtype in each cell was taken as the expression value of this subtype in each cell. 2 . The $R$ package GSVA (version 1.38.2) [37] was used to evaluate the expression activity of PAM50 in 12 samples from 10 patients. 3. The $\mathrm{R}$ package genefu (version 2.22.1) [38] was applied for PAM50 classification of individual cells. 


\section{Analysis of the expression characteristics of IncRNAs in tumor cells}

To explore whether lncRNAs can also be used as markers for subtyping BC, such as PAM50, we compared the expression characteristics of lncRNAs and PAM50 by the following aspects: 1 . Expression density of IncRNA/PAM50 in each cell and 2. Expressed cell proportion of each lncRNA/PAM50. And density curve figures were drawn by $R$ packages stats (version 4.0.3).

To further illustrate that lncRNAs are better markers than PAM50, we performed the following steps: 1 . The Pearson correlation coefficient between the lncRNAs and PAM50 genes in cells was compared. The larger the Pearson correlation coefficient, the smaller the heterogeneity. 2. Compare the CV (coefficient of variation = standard deviation/mean) of lncRNAs and PAM50 genes, with the CV reflecting the degree of dispersion of expression of lncRNA/PAM50. The larger the CV, the higher the heterogeneity. The Wilcoxon test was used to verify the statistical significance of the above two steps.

\section{Identification of IncRNA subtypes}

To identify subtypes of BC more accurately, and save calculating time and cost, M3Drop [39] was applied to select important lncRNA features that have key effects on subtyping. Since the Michaelis-Menten equation is a nonlinear convex function, the lncRNAs in the upper/ right (which means FDR $<0.05$ ) of the Michaelis-Menten model are differentially expressed lncRNAs between cell populations in the data set, which indicates that they have key roles in subtyping. Threshold was set to FDR < 0.05 .

Six unsupervised clustering methods, including unsupervised clustering methods developed based on bulk sequencing data, including hierarchical clustering (HC), NMF [40] and unsupervised clustering methods developed specifically for single-cell sequencing data, including SC3 [41], SIMLR [42], RaceID [43] and Seurat [44], were used to perform cluster analysis based on important lncRNA expression profiles of tumor cells.

By comparing the average rouge score (the higher the rouge value, the higher the purity of the cell cluster and the better the clustering method) calculated by the $R$ package ROUGE (version 1.0) [45], we selected the most appropriate clustering method.

\section{Identification of markers of IncRNA subtypes}

SC3 was used to identify the lncRNA markers of each lncRNA subtype, and the threshold was set to auroc $\geq 0.75, P<0.01$. In order to verify the representativeness of the obtained lncRNA markers, we performed cluster analysis again by using SC3 based on the lncRNA markers of subtypes, and compared them with the previous clustering results. The indicator adjusted Rand index
(ARI) is used to measure the consistency of the two clustering results and is calculated by python module 'scikit-learn'. The closer the ARI id to 1, the higher the degree of consistency between the two clustering results, and the more representative the identified lncRNA markers are.

\section{Enrichment analysis}

To further clarify the functional characteristics of each lncRNA subtype, we directly identified the differentially expressed genes (DEGs) of lncRNA subtypes and enriched DEGs with GO term functions. The $\mathrm{R}$ package scran (version 1.18.5) [46], a method to find candidate marker genes for cell clusters by detecting differential expression between cell clusters, was used to identify DEGs in each subtype, with the screening threshold set as follows: the $|\log \mathrm{FC}|$ between subtypes was greater than or equal to 1 , and the FDR was less than 0.01 . Based on these DEGs, the enrichment of GO functions was performed using the $\mathrm{R}$ package clusterProfiler (version 3.18.1) [47], and $P<0.05$ was selected as the threshold of GO terms for significant enrichment.

\section{Survival analysis}

To verify the effect of different subtypes on the survival prognosis of patients, tissue expression profiling data and corresponding patient survival information from TCGA-BRCA was used to perform survival analysis. Since the expression profile of TCGA cannot completely cover 44 lncRNA markers of 7 lncRNA subtypes, we used the DEGs of each lncRNA subtype to calculate the Pearson correlation between TCGA patients and the 7 lncRNA subtypes. Hierarchical clustering was performed based on the correlation matrix to group patients. Kaplan-Meier survival curves of different patient groups were generated using the $\mathrm{R}$ package survival (version 3.2.7).

\section{Candidate drugs for each IncRNA subtypes}

To provide novel insight for the clinical treatment of $B C$ based on the characteristics of new IncRNA subtypes and further explore the treatment strategy of $\mathrm{BC}$ at the single-cell level, we identified candidate targets and drugs for each lncRNA subtype according to the following steps: after removing the duplicate GO terms between the IncRNA subtypes, the specific GO terms of each lncRNA subtype were obtained. Then, the Pearson correlation between lncRNA markers and genes of specific GO terms was calculated by the $\mathrm{R}$ package psych (version 2.0.12), and we selected genes with $\mid$ cor $\mid>0.2$ [48] and $P<0.05$ as candidate regulatory targets for lncRNAs. The R package scran (version 1.18.5) [46] was used to identify DEGs between tumor cells and nontumor cells. Intersection of candidate regulatory target 
genes of lncRNA and DEGs between tumor cells and nontumor cells were served as candidate targets for each lncRNA subtype. Then we downloaded the drug-target information from three databases (DrugBank [49], TTD [50], and Drug Repurposing Hub [51]), integrated candidate targets of each subtype and drug-target interaction information, and selected drugs appearing in more than two databases as candidate drugs for each subtype.

\section{Results}

\section{IncRNAs as better subtyping markers than PAM50}

Figure $2 \mathrm{a}, \mathrm{b}$, and $\mathrm{c}$ show that tumor heterogeneity mainly comes from the heterogeneity of tumor cells and Fig. $2 b$ and $c$ show that the heterogeneity of tumor cells is greater than that of nontumor cells. Figure $2 b$ indicate that there is a wide range of heterogeneity between tumor cells even within tumor cells of the same PAM50 subtype. In Fig. 2b, we also found that samples from the same PAM50 subtype were not gathered together at the single cell level. For example, $\mathrm{BC} 01$ and $\mathrm{BC} 02$ are two separate parts, but both belonging to luminal A, which indicates that there is a wide range of intratumoral heterogeneity in PAM50 subtypes. This shows obvious patient variability, which presents heterogeneity at the patient level.

Based on the above phenomenon, we further evaluated the molecular characteristics of PAM50 subtypes at the single-cell level (Figure S1) by expression density maps of PAM50 subtypes in 10 patients. For all samples except $\mathrm{BC} 06$, the corresponding subtype curve cannot be separated from the other three. In particular, $\mathrm{BC} 03$, which belongs to luminal $\mathrm{B}$, was highly expressed in the expression density map, and its signature genes wereHER2enriched. A previous study showed that luminal B subtypes can express ERBB2/HER2 genes [52]. This shows that the PAM50 subtypes do not completely express the heterogeneity characteristics of single tumor cell.
In addition, the expression activity (Figure S2) was displayed to evaluate the expression status of PAM50 subtypes in 10 patients. Taking $\mathrm{BC} 01$ as an example, the signature genes of luminal A have different expression trends in different cells (some are highly expressed and some are expressed at low levels), and they cannot be well distinguished from at gene expression of the other three PAM50 subtypes. Moreover, the expression pattern of PAM50 subtypes varies from cell to cell, and each sample has expression characteristics of multiple PAM50 subtypes.

Therefore, we further predicted the PAM50 subtype of individual cells. From the PAM50 classification results of individual cells (Fig. 3), multiple cells belonging to one PAM50 subtype at the tissue level will belong to different PAM50 subtypes, which indicates that the effect of PAM50 subtypes is not ideal and cannot reveal the complete intratumor heterogeneity of BC. Therefore, a new subtyping method is needed to analyze the heterogeneity of $\mathrm{BC}$ cells.

We supposed that subtyping markers should meet the following criteria: 1 . Markers should be highly expressed in a small number of cells, and expressed close to 0 in most cells and 2 . In a single cell, only a small number of markers are highly expressed, and the expression of others is close to 0. Here, we compared the expression consistency of lncRNAs and PAM50 (Fig. 4a-b, Additional file 1) to illustrate that lncRNAs can be similar to PAM50 in characterizing BC cells. Then, we compared the expression heterogeneity of lncRNAs and PAM50 (Fig. 4c-d) to assess whether lncRNAs are more suitable than PAM50 as new markers for subtyping of BC.

From Fig. 4a-b, we found that for each lncRNA expressed in high abundance in a few of cells, PAM50 was too, which indicates that lncRNA is similar to PAM50, that is the expression of lncRNAs in cancer cells is also heterogeneous, and thus, IncRNAs can be
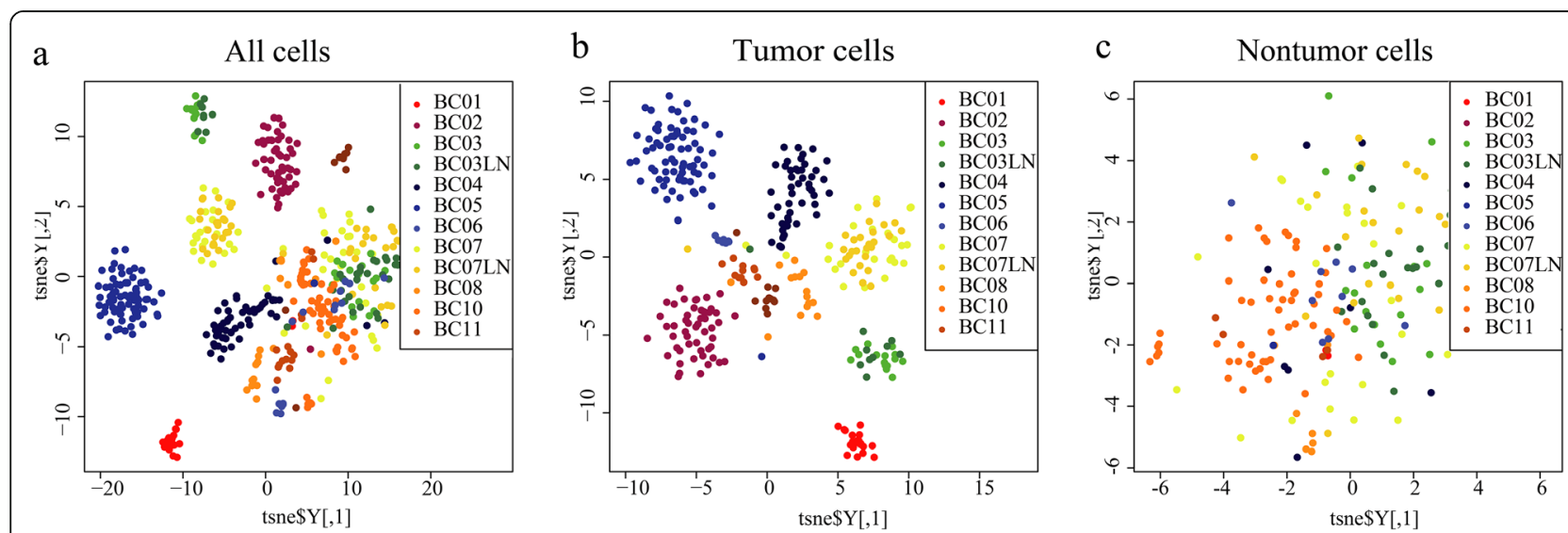

Fig. 2 Tsne display of all cells (a), tumor cells (b), and nontumor cells (c) in 11 patients. BC01-BC02: Luminal A, BC03: Luminal B, BC04-BC06: HER2enriched, BC07-BC08, BC10-BC11: Basal-like/TNBC 

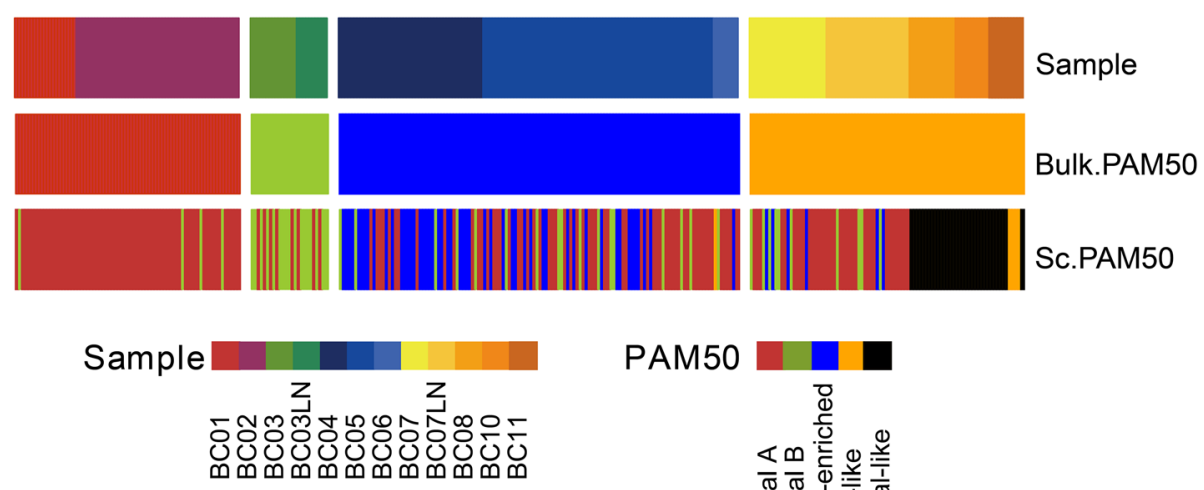

PAM50

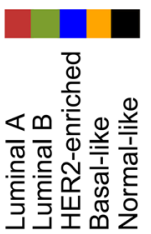

Fig. 3 Sample source, bulk PAM50 subtype, predicted PAM50 subtypes of individual cells

used as markers for reclassifying BC cells. In Fig. 4c, except BC03LN and BC06 (their cell number is too small to accurately reflect the overall level of heterogeneity distribution), the intercellular similarity of lncRNAs in other samples is lower than that of PAM50. Figure 4d shows that the CV of lncRNAs is significantly higher than that of PAM50, indicating that the degree of dispersion of lncRNAs between tumor cells is stronger and that the intercellular heterogeneity of lncRNAs is higher than that of PAM50. Therefore, lncRNAs can more significantly represent the heterogeneity of tumor cells, which means lncRNAs might be more suitable as subtyping markers for $\mathrm{BC}$.

\section{Identification of new subtypes of breast cancer}

In the expression profile of lncRNAs, some lncRNAs have weak correlation with $\mathrm{BC}$ heterogeneity, which will interfere with subtyping results. Therefore, we first identified important lncRNAs. A total of 119 lncRNAs with a multiple correction FDR $<0.05$ were obtained (Fig. 5a) for further analysis. Then, 6 clustering methods were performed on important lncRNAs in 317 tumor cells (Fig. 5b).

We prefer to select the method meeting the following conditions: 1 . Complete separation between clusters, 2 . The number of clusters was at least greater than the number of PAM50 subtypes, and 3. The average rouge score is highest. The average rouge scores of the six methods are 0.999921 (SC3), 0.999641 (HC), 0.994104 (NMF), 0.999166 (RaceID), 0.997553 (Seurat) and 0.998465 (SIMLR), respectively. It can be seen that SC3 is the best. From Fig. 5b, the clustering visualization of SC3 (Figure S3) is most obvious, and the number of clusters (lncRNA subtypes) is 7. In Fig. 5c, it can be seen that the cells of the same PAM50 subtype are not always similar. Tumor cells of the same PAM50 subtype were dispersed in at least two lncRNA subtypes. In the
lncRNA subtypes of SC3, except for a few cells, the clustering results of other cells can ensure that the closely related clusters are separated from each other.

Resubtyping strategies based on the expression of important lncRNAs better solves the problem of unclear boundaries of subtypes due to intratumoral heterogeneity in BC. Since the gold standard for the molecular classification of BC is PAM50 subtypes, we compared lncRNA subtypes with PAM50 subtypes (Fig. 6a-b). Compared with PAM50 subtypes, lncRNA subtypes can reveal the phenomenon of multiple lncRNA subtypes in each PAM50 subtype at the single-cell level. We have counted the types and proportions of IncRNA subtypes in each patient (Fig. 6c-d). Some patients contain cells of multiple lncRNA subtypes at the same time, which reflects the high resolution of typing based on the single cell sequencing data. For example, patients $\mathrm{BC} 02$, $\mathrm{BC} 03$, $\mathrm{BC} 04, \mathrm{BC} 5, \mathrm{BC} 07$ and $\mathrm{BC} 08$, have at least two PAM50 subtypes. For these patients, the cell number of each lncRNA subtype was different. We defined the lncRNA subtype with a highest proportion of cancer cells as the major/dominant subtype, and other lncRNA subtypes were minor subtypes. Detailed information about the subtypes of each patient is shown in Additional file 2.

\section{The IncRNA markers of new IncRNA subtypes}

Forty-four lncRNA markers, including 10, 5, 3, 3, 1, 10, and 12 lncRNAs of 7 lncRNA subtypes, were obtained (Fig. 7, Additional file 3). SC3 was reused to perform unsupervised clustering for 317 tumor cells based on 44 lncRNA markers to assess the representativeness of lncRNA markers by comparing the number of clusters with those of the previous lncRNA subtypes. The optimal number of clusters of markers is the same as the previous number of clusters. The consistency of the marker clustering results with the previous lncRNA subtyping results was high $(\mathrm{ARI}=0.928)$. This illustrates 





(See figure on previous page.)

Fig. 4 Comparison of the expression consistency of IncRNAs and PAM50. a Proportion density distribution of IncRNAs and PAM50 in each cell. The abscissa indicates the level of expression, and the ordinate indicates the density of expressed IncRNAs or APM50. $\mathbf{b}$ The expression density distribution of each IncRNA and each signature gene of PAM50 in cells. The abscissa indicates the expression level, and the ordinate indicates the density of the expressed cells. c. Comparison of expression heterogeneity of IncRNAs and PAM50 in 10 patients. The abscissa represents the samples and the ordinate represents the Pearson similarity between cells. Red represents IncRNAs and green represents PAM50. d CV of IncRNAs and PAM50 for 10 patients. The abscissa indicates IncRNAs and PAM50, and the ordinate indicates the CV

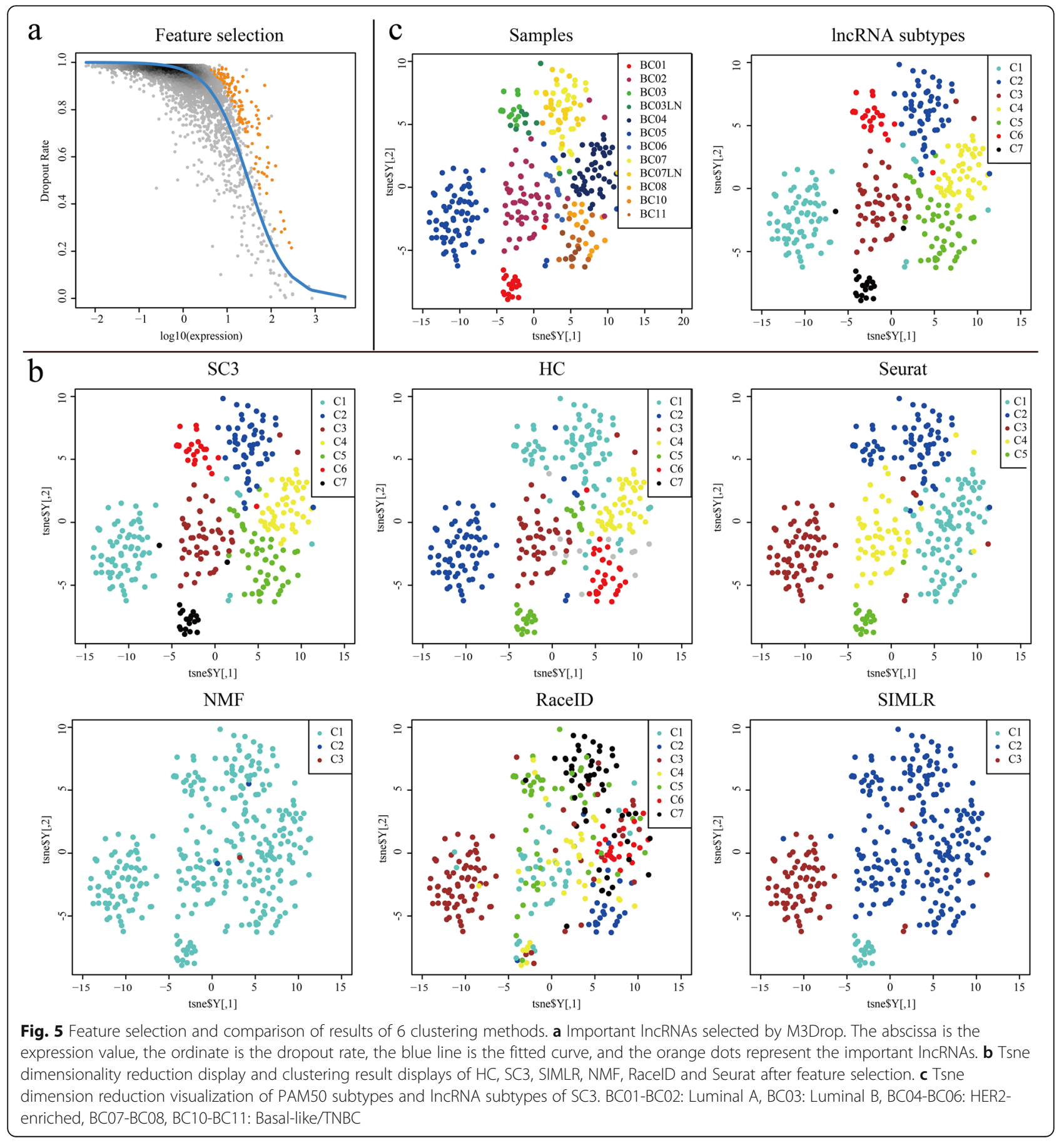




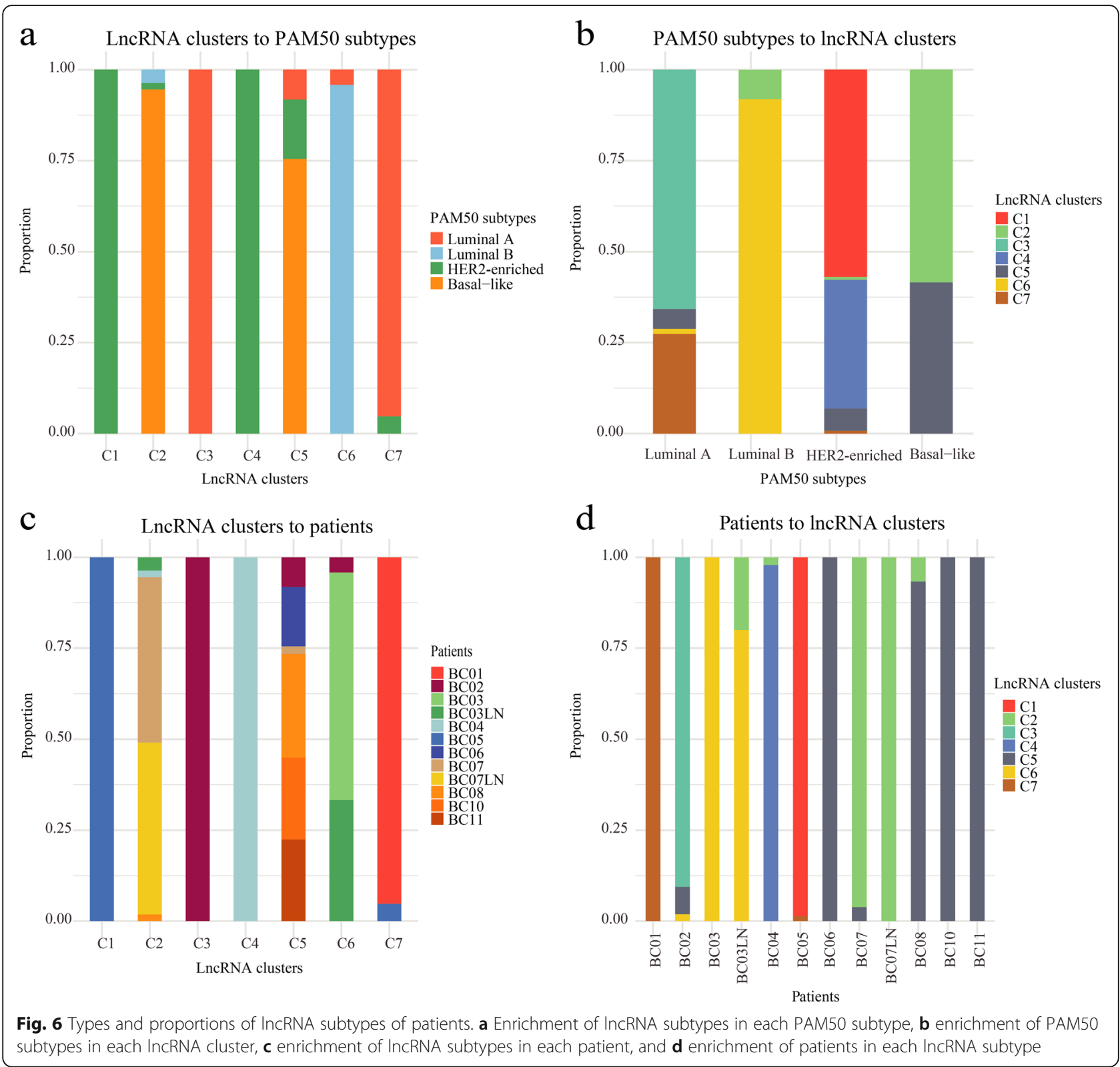

that the identified lncRNA markers of each subtype are sufficient to distinguish the new lncRNA subtypes.

\section{Biological characteristics of IncRNA subtypes}

To better characterize the biological functions of each lncRNA subtype, we performed enrichment analysis of DEGs of each lncRNA subtype to obtain their specific functional characteristics. When the threshold was $|\operatorname{logFC}| \geq 1$ and FDR $<0.01$, the numbers of DEGs of each subtype identified were 427, 332, 652, 419, 248, 526 and 942 (Additional file 4). Significantly enriched GO terms were selected at $P<0.05$ and are shown in Additional file 5. Each subtype has specific functional characteristics. For example, C3 is related to transcriptional functions, including RNA degradation, RNA splicing, RNA stability regulation, and RNA localization [53]. The RNA-binding protein NONO that promotes BC proliferation [43] is involved in nuclear speck of CC (cellular component) and RNA splicing of BP (biological process).

\section{Survival validation based on TCGA patients}

Since there is no survival time information in our data, we downloaded a new set of data from 1092 BC patients from TCGA for survival analysis. The Pearson correlation between the patients and the 7 lncRNA subtypes is shown in Fig. 8a, and patients were divided into 3 populations. Population 1 has the highest correlation with $\mathrm{C}$, 


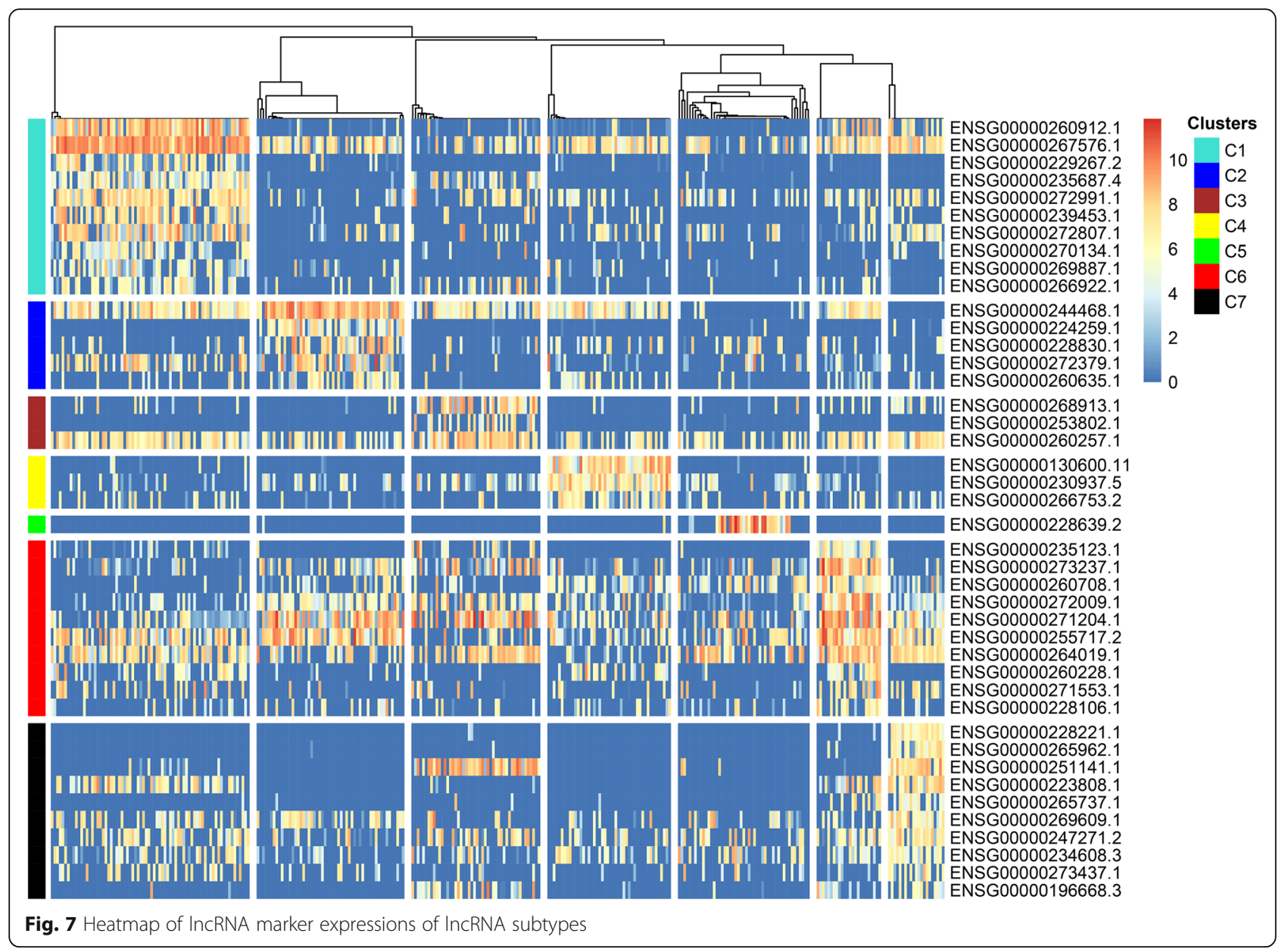

medium correlation with $\mathrm{C} 1$ and $\mathrm{C} 3$, and the lowest correlation with $\mathrm{C} 2$, and the other ncRNA subtypes have no difference from population 2. In contrast, population 2 has the highest correlation with $\mathrm{C} 2$ and the lowest correlation with $\mathrm{C} 1$ and $\mathrm{C} 3$. Population 3 has the highest correlation with $\mathrm{C} 1$ and $\mathrm{C} 7$, and the lowest correlation with $\mathrm{C} 4$ and $\mathrm{C} 6$. The survival curves of the 3 populations are shown in Fig. 8b. Population 2 had the lowest survival rate and population 3 had the highest survival rate.
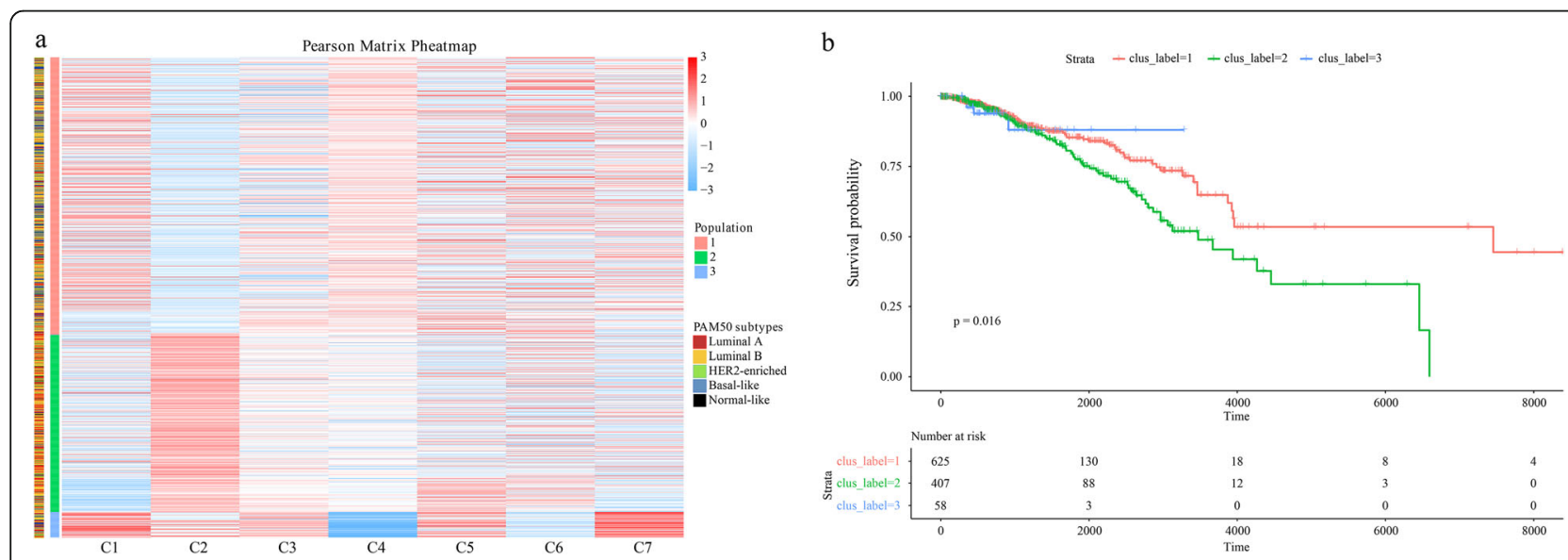

Fig. 8 Results of survival analysis. a Heatmap of the Pearson coefficient between TCGA patients and 7 IncRNA subtypes. b The survival curves of 3 populations of TCGA patients 
To verify the difference in survival curves among the 3 populations, we tested the impact of lncRNA markers of 7 lncRNA subtypes on the survival or prognosis of patients or the development of $\mathrm{BC}$ through the literatures.

For population 2, there is no literature to show the correlation between lncRNA markers of $\mathrm{C} 2 / \mathrm{C} 3$ and $\mathrm{BC}$, and thus, so we focused on the impact of IncRNA markers of C1 on BC. LINC00993, a lncRNA marker of $\mathrm{C} 1$, acts as a tumor suppressor [54]. The lowest correlation with $\mathrm{C} 1$ confirms that population 2 has the lowest survival rate.

For population 3, we focused on markers of $\mathrm{C} 1, \mathrm{C} 4$ and $\mathrm{C} 6$ because there are no reports about the relationship of markers of C7 and BC. H19 is a lncRNA marker of $\mathrm{C} 4$. Studies show that $\mathrm{H} 19$ overexpression in $73 \%$ of $\mathrm{BC}$ tissues enhances $\mathrm{BC}$ cell migration [55]. It mediates the resistance of $\mathrm{BC}$ cells to paclitaxel, trastuzumab and tamoxifen for [55-57]. It is associated with poor prognosis in BC patients, particularly in TNBC subtype [58]. DSCAM-AS1 and SNHG1 are lncRNA markers of C6. DSCAM-AS1 promoted the proliferation and invasion of BC cells by reducing miR-204-5p and inhibiting miR204-5p expression [59]. SNHG1 promotes BC [60] and impedes the immune escape of $\mathrm{BC}$ [61]. The highest correlation with $\mathrm{C} 1$ and the lowest correlation with $\mathrm{C} 4$ and $\mathrm{C} 6$ confirm that population 3 has the highest survival rate. However, since the longest survival time of population 3 patients is only 3283 days, the trend of the survival curve in the second half of population 3 cannot be predicted. For population 1, the highest correlation with $\mathrm{C} 4$ and medium correlation with $\mathrm{C} 1$ verified the medium survival rate of population 1 .

\section{Precision treatment for patients with multiple subtypes}

To explore treatment strategies based on the new subtyping result, it is also necessary to identify candidate therapeutic drugs for single-cell lncRNA subtypes. Drugs can indirectly target lncRNAs to exert antitumor efficacy by regulating lncRNA-related pathways or regulators. Therefore, we indirectly targeted lncRNA by identifying drugs that target IncRNA regulatory genes. For 7 IncRNA subtypes, 210 candidate drugs were identified and are shown in Table 1 and Additional file 6. We conducted direct (drug-disease relationships) or indirect (drug-target, target-disease relationships) literature verification on candidate drugs. In addition, the total literature verification rate is $86.2 \%$. We found that some drugs are for only one lncRNA subtype, such as imatinib, which is only for subtype $\mathrm{C} 1$, and some drugs are suitable for multiple subtypes, such as canfosfamide, which is a therapeutic drug for the C4, C5 and C6 subtypes. Among these predicted drugs, we found that some drugs are currently used to treat PAM50 subtypes. For example, candidate drugs for $\mathrm{C} 1$, including trastuzumab, pertuzumb, lapatinib and sorafenib are commonly used for HER2-enriched subtypes. Fulvestrant, a commonly used drug for luminal A, is on the candidate drug list of C3. The history of TNF- $\alpha$ is closely related to the history of tumor immunotherapy [62]. TNF- $\alpha$ is one of the most important pro-inflammatory cytokines found in breast cancer, mainly secreted by M1 activated macrophages [63]. TNF- $\alpha$ belongs to the TNF/TNFR superfamily and is considered to be one of the most promising anticancer factors [64]. TNF- $\alpha$ affects the development of $\mathrm{BC}$ at all stages, including the development of primary tumors, EMT, metastasis and disease recurrence [65]. Therefore, a treatment plan related to TNF- $\alpha$ in BC has been produced: neutralization of endogenous TNF- $\alpha$ by TNF antagonists [65]. In some preclinical studies, TNF$\alpha$ antagonists have been shown to effectively inhibit the growth and spread of BC [65]. The predicted TNFtargeted drugs are MSX-122, nimesulide, adalimumab, AME-527, certolizumab pegol, etanercept, golimumab, infliximab, and thalidomide. Etanercept can bind to TNF- $\alpha$, thereby inhibiting its biological activity [65]. Infliximab inhibits tumor growth and lymph node metastasis by combining molecular pathways mediated by TNF- $\alpha$ [66]. In addition, when TNF- $\alpha$ stimulates BC, it will activate the transcription factors NFk $\beta$ and cJun, drive the transcription of EMMPRIN and MIF genes, and induce the increase of MMP secreted by macrophages in TME. It has been found to promote tumor cell invasion and metastasis [67]. The drugs that target MMP family genes are marimastat, SC-74020, and UK356618. Among which, marimastat can prevent tumor cell invasion and metastasis $[68,69]$.

We hypothesized that the presence of multiple singlecell subtypes in a patient is the cause of treatment failure or even tumor recurrence. For patients with multiple subtypes, clinically, the patient may only display the phenotypic characteristics of the dominant subtype, and the phenotypic characteristics of minor/secondary subtypes will be covered up. Only treating the dominant subtype may result in poor treatment effects. For example, lncRNA subtype $\mathrm{C} 1$ accounted for the majority/ dominance in patient $\mathrm{BC} 05$, followed by $\mathrm{C} 7$. Clinically, the tumor phenotype characteristics of $\mathrm{C} 1$ may cover those of the $\mathrm{C} 7$ subtype, and the patient phenotype apparently represents the $\mathrm{C} 1$ subtype. Usually, according to the current treatment strategy, $\mathrm{BC} 05$ is treated according to the $\mathrm{C} 1$ subtype. During the process of treatment, $\mathrm{C} 1$ cells are gradually eliminated, and $\mathrm{C} 7$ cancer cells appear, leading to drug resistance or a potential risk of recurrence. Therefore, for patients with multiple subtypes, we proposed new treatment strategies that should use targeting multi-subtype drugs or combinations of targeting single-subtype drugs to simultaneously treat the patient with multiple subtypes. For $\mathrm{BC} 05$, we can 
Table 1 Information of candidate drugs for each IncRNA subtype

\begin{tabular}{|c|c|c|c|c|c|}
\hline $\begin{array}{l}\text { LncRNA } \\
\text { subtypes }\end{array}$ & $\begin{array}{l}\text { Numbers } \\
\text { of drugs }\end{array}$ & $\begin{array}{l}\text { Numbers of drugs only } \\
\text { for one subtype }\end{array}$ & $\begin{array}{l}\text { Numbers of drugs shared } \\
\text { with other subtypes }\end{array}$ & $\begin{array}{l}\text { IncRNA subtypes } \\
\text { sharing drugs }\end{array}$ & $\begin{array}{l}\text { Drugs shared with } \\
\text { other subtypes }\end{array}$ \\
\hline \multirow[t]{2}{*}{$\mathrm{Cl}$} & 33 & 31 & 2 & $\mathrm{C} 1 ; \mathrm{C} 2$ & BMS-536924 \\
\hline & & & & $\mathrm{C} 1 ; \mathrm{C} 2 ; \mathrm{C} 6 ; \mathrm{C} 7$ & TW-37 \\
\hline \multirow[t]{5}{*}{$C 2$} & 18 & 13 & 5 & $\mathrm{C} 1 ; \mathrm{C} 2$ & BMS-536924 \\
\hline & & & & $\mathrm{C} 2 ; \mathrm{C} 6$ & AMD-070 \\
\hline & & & & & MSX-122 \\
\hline & & & & & Plerixafor \\
\hline & & & & $\mathrm{C} 1 ; \mathrm{C} 2 ; \mathrm{C} 6 ; \mathrm{C} 7$ & TW-37 \\
\hline C3 & 45 & 44 & 1 & C3; C6; C7 & R547 \\
\hline C4 & 39 & 38 & 1 & C4; C5 & Curcumin \\
\hline \multirow[t]{3}{*}{ C5 } & 16 & 13 & 3 & $\mathrm{C} 4 ; \mathrm{C} 5$ & Curcumin \\
\hline & & & & C5; C6 & Canfosfamide \\
\hline & & & & & Ezatiostat \\
\hline \multirow[t]{12}{*}{ C6 } & 34 & 22 & 12 & $\mathrm{C} 1 ; \mathrm{C}_{2} ; \mathrm{C} 6 ; \mathrm{C7}$ & TW-37 \\
\hline & & & & $\mathrm{C} 2 ; \mathrm{C} 6$ & AMD-070 \\
\hline & & & & & MSX-122 \\
\hline & & & & & Plerixafor \\
\hline & & & & C3; C6; C7 & R547 \\
\hline & & & & $\mathrm{C} 5 ; \mathrm{C} 6$ & Canfosfamide \\
\hline & & & & & Ezatiostat \\
\hline & & & & C6; C7 & ABT-737 \\
\hline & & & & & Obatoclax \\
\hline & & & & & Phosphonothreonine \\
\hline & & & & & SNS-032 \\
\hline & & & & & THZ1 \\
\hline \multirow[t]{7}{*}{$C 7$} & 42 & 35 & 7 & $\mathrm{C} 1 ; \mathrm{C} 2 ; \mathrm{C} 6 ; \mathrm{C} 7$ & TW-37 \\
\hline & & & & $\mathrm{C} 3 ; \mathrm{C6} ; \mathrm{C7}$ & R547 \\
\hline & & & & C6; C7 & ABT-737 \\
\hline & & & & & Obatoclax \\
\hline & & & & & Phosphonothreonine \\
\hline & & & & & SNS-032 \\
\hline & & & & & THZ1 \\
\hline
\end{tabular}

use a drug shared by two subtypes, such as TW-37, which is confirmed to effectively induces apoptosis in a dose-dependent manner [70] or a combination of drugs to target $\mathrm{C} 1$ and $\mathrm{C} 7$ subtypes, such as pertuzumab [71] and melatonin [72]. Treatment strategies of other patients are in Additional file 7.

\section{Discussion}

Accurate classification can improve the accuracy and success rate of subtype diagnosis, obtain the good prognosis of each subtype, and greatly help the exploration of precise treatment strategies. In our research, we used IncRNA expression profiles of single cells to retype BC to better highlight the heterogeneity among cancer cells, identify precise subtypes, and performing more precise treatment.

PAM50 molecular subtypes are based on bulk sequencing and cannot completely reveal intratumoral heterogeneity. The subtyping of $\mathrm{BC}$ at the single-cell level is mainly based on mRNAs/genes, still leaving some room for improvement. In this article, we first demonstrated that lncRNAs are more suitable as markers for presenting the intratumoral heterogeneity of $\mathrm{BC}$ by comparing the expression consistency and variance of mRNAs and lncRNAs among cells and found that the expression variance of lncRNAs was higher than that of mRNAs. Therefore, we used single-cell lncRNA expression data to retype 317 tumor cells from 12 samples of $10 \mathrm{BC}$ 
patients, identified new lncRNA subtypes, their markers and specific functional characteristics, and performed survival analysis. At the same time, we compared lncRNA subtypes with the PAM50 subtype, which is the gold standard for $\mathrm{BC}$ classification, and found that lncRNA subtypes can more accurately reveal intratumoral heterogeneity.

When subtyping by PAM50 is to cluster patients, each patient shows one subtype. While subtyping based on single-cell lncRNA markers is the clustering of cells, we also found that some patients had multiple lncRNA subtypes. We also found that some patients had multiple lncRNA subtypes. If these patients with multiple subtypes are treated only for the tumor cells of the major/dominant subtype, neglecting those of minor subtypes based on the current treatment strategy, the activities of these tumor cells of minor subtypes would be highlighted with the disappearance of tumor cells of major subtype in the progress of treatment, which would result in drug resistance and tumor recurrence. Based on this, we further identified candidate therapeutic drug targets and corresponding drugs for each lncRNA subtype to explore new treatment strategies. The literature verification rate of predicted drugs is $86.2 \%$, which reflects the accuracy of our results to some extent. For these patients, we propose a new treatment strategy in which we should use one targeting multi-subtype drug or choose a combination of drugs targeting only one subtype to improve the treatment effect. Specifically, we prefer to recommend the former with fewer side effects. For $\mathrm{BC} 05$, we recommend $\mathrm{TW}-37$ shared by $\mathrm{C} 1$ and $\mathrm{C} 7$ subtypes rather than the combination of pertuzumab and melatonin.

In this article, some positive results have been obtained and also providing new perspectives and foundations for further $\mathrm{BC}$ research, but these results need to be verified further, especially by population investigations in the future.

\section{Supplementary Information}

The online version contains supplementary material available at https://doi. org/10.1186/s12885-021-08617-7.

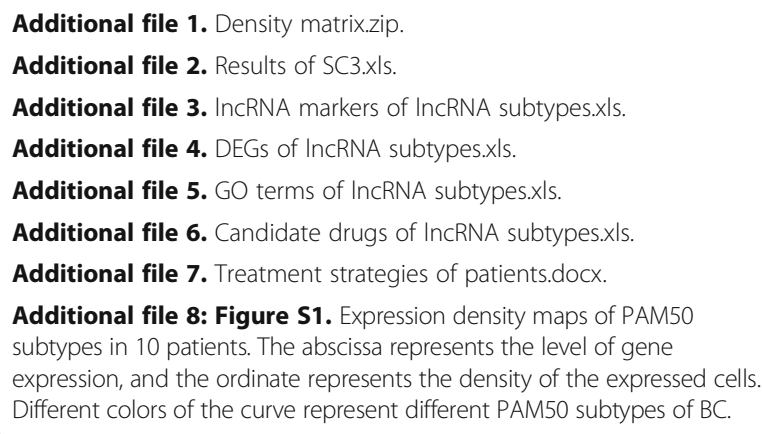

Additional file 9: Figure S2. Heatmap of the expression activity of PAM50 in 10 patients. In almost all samples, multiple subtypes are highly expressed in different cells at single-cell resolution.

Additional file 10: Figure S3. Cluster evaluation of SC3 to determine the best cluster number. a). Consensus matrix diagram of the SC3 results. A similarity of 0 (blue) indicates that two cells are always assigned to different clusters. In contrast, a similarity of 1 (red) indicates that two cells are always assigned to the same cluster. b). Average silhouette width of SC3 results. The average silhouette width varies from 0 to 1 , where 1 represents a perfectly block-diagonal consensus matrix. The best clustering is achieved when the average silhouette width is close to 1.

\section{Acknowledgements}

Not applicable.

\section{Authors' contributions}

$X J C$ designed the project, DN Z and $Y Z$ designed the methods of the article, QK M and F X collected data and conducts calculation and analysis. $Y Z$ analyzed the results. $X J C$ and $Y Z$ wrote the paper. All authors reviewed the manuscript. $Z Q L$ participated in the revision work of this paper. $Y Z$, DN Z, QK M and ZQ L contributed equally to this paper. The authors read and approved the final manuscript.

\section{Funding}

This work was supported by the National Natural Science Foundation of China [Grant No. 61671191, 61971166].

\section{Availability of data and materials}

The datasets used in this article is download from Gene Expression Omnibus (GEO) (https://www.ncbi.nlm.nih.gov/geo/query/acc.cgi?acc=GSE75688) with accession number GSE75688 [26]. And all data generated during this study are included in supplementary information files.

\section{Declarations}

Ethics approval and consent to participate

Not applicable.

\section{Consent for publication}

Not applicable.

\section{Competing interests}

The authors declare that the research was conducted in the absence of any commercial or financial relationships that could be construed as a potential conflict of interest.

\section{Author details}

${ }^{1}$ College of Bioinformatics Science and Technology, Harbin Medical University, Harbin 150081, Heilongjiang Province, P. R. China. ${ }^{2}$ Department of Pharmacy, The First Affiliated Hospital, Harbin Medical University, Harbin 150001, Heilongjiang Province, P. R. China.

Received: 8 December 2020 Accepted: 15 July 2021

Published online: 13 August 2021

\section{References}

1. Torre LA, Bray F, Siegel RL, Ferlay J, Lortet-Tieulent J, Jemal A. Global cancer statistics, 2012. CA Cancer J Clin. 2015;65(2):87-108. https://doi.org/10.3322/ caac. 21262.

2. Januškevičienè I, Petrikaitè $V$. Heterogeneity of breast cancer: the importance of interaction between different tumor cell populations. Life Sci. 2019;239:117009. https://doi.org/10.1016/j.lfs.2019.117009.

3. Cui Q, Tang J, Zhang D, Kong D, Liao X, Ren J, et al. A prognostic eightgene expression signature for patients with breast cancer receiving adjuvant chemotherapy. J Cell Biochem. 2020;121:3923-34. https://doi.org/1 0.1002/jcb.29550

4. Anderson WF, Rosenberg PS, Prat A, Perou CM, Sherman ME. How Many Etiological Subtypes of Breast Cancer: Two, Three, Four, Or More? J Natl Cancer Inst. 2014;106(8):dju165. 
5. van't Veer LJ, Dai H, van de Vijver MJ, He YD, Hart AAM, Mao M, et al. Gene expression profiling predicts clinical outcome of breast cancer. Nature. 2002; 415(6871):530-6.

6. Cardoso F, van't Veer $\sqcup$, Bogaerts J, Slaets L, Viale G, Delaloge S, et al. 70gene signature as an aid to treatment decisions in early-stage breast Cancer. N Engl J Med. 2016;375(8):717-29. https://doi.org/10.1056/NEJMoa1 602253

7. Sparano JA, Gray RJ, Makower DF, Pritchard Kl, Albain KS, Hayes DF, et al. Prospective validation of a 21-gene expression assay in breast Cancer. N Engl J Med. 2015;373(21):2005-14. https://doi.org/10.1056/NEJMoa1510764.

8. Parker JS, Mullins M, Cheang MCU, Leung S, Voduc D, Vickery T, et al. Supervised risk predictor of breast Cancer based on intrinsic subtypes. J Clin Oncol. 2009;27(8):1160-7. https://doi.org/10.1200/JCO.2008.18.1370.

9. Koboldt DC, Fulton RS, McLellan MD, Schmidt H, Kalicki-Veizer J, McMichael JF, et al. Comprehensive molecular portraits of human breast tumours. Nature. 2012;490(7418):61-70.

10. Perou CM, Sørlie T, Eisen MB, van de Rijn M, Jeffrey SS, Rees CA, et al. Molecular portraits of human breast tumours. Nature. 2000;406(6797):74752. https://doi.org/10.1038/35021093.

11. Prat A, Parker JS, Fan C, Perou CM. PAM50 assay and the three-gene model for identifying the major and clinically relevant molecular subtypes of breast cancer. Breast Cancer Res Treat. 2012;135(1):301-6. https://doi.org/10.1007/ s10549-012-2143-0.

12. Gadi VK, Davidson NE. Practical Approach to Triple-Negative Breast Cancer. J Oncol Pract. 2017; 13(5):293-300

13. Wiechmann L, Sampson M, Stempel M, Jacks LM, Patil SM, King T, et al. Presenting Features of Breast Cancer Differ by Molecular Subtype. Ann Surg Oncol. 2009:16(10):2705-10.

14. Wörmann B. Breast cancer: basics, screening, diagnostics and treatment Med Monatsschr Pharm. 2017:40(2):55-64.

15. Palma G, Frasci G, Chirico A, Esposito E, Siani C, Saturnino C, et al. Triple negative breast cancer: looking for the missing link between biology and treatments. Oncotarget. 2015;6(29):26560-74. https://doi.org/10.18632/ oncotarget.5306.

16. Vincent-Salomon A, Gruel N, Lucchesi C, Macgrogan G, Aurias A Identification of typical medullary breast carcinoma as a genomic subgroup of basal-like carcinomas, a heterogeneous new molecular entity. Breast Cancer Res. 2007;9(2):R24. https://doi.org/10.1186/bcr1666.

17. Gonçalves A, Sabatier R, Charafejauffret E. Triple-negative breast cancer histoclinical and molecular features, therapeutic management and perspectives. Bull Cancer. 2013;100(5):453-64.

18. Goldhirsch A, Wood WC, Coates AS, Gelber RD, Thürlimann B, Senn HJ. Strategies for subtypes-dealing with the diversity of breast cancer: highlights of the St Gallen international expert consensus on the primary therapy of early breast Cancer 2011. Ann Oncol. 2011;22(8):1736-47. https:// doi.org/10.1093/annonc/mdr304.

19. Kim HK, Park KH, Kim Y, Park SE, Lee HS, Lim SW, et al. Discordance of the PAM50 intrinsic subtypes compared with immunohistochemistry-based surrogate in breast Cancer patients: potential implication of genomic alterations of discordance. Cancer Res Treat. 2019;51(2):737-47. https://doi. org/10.4143/crt.2018.342

20. Zhu S, Qing T, Zheng $Y$, Jin L, Shi L. Advances in single-cell RNA sequencing and its applications in cancer research. Oncotarget. 2017;8(32):53763-79. https://doi.org/10.18632/oncotarget.17893.

21. Shirai M, Taniguchi T, Kambara H. Emerging Applications of Single-Cell Diagnostics. In: Tang NLS, Poon T, editors. Chemical Diagnostics: From Bench to Bedside. Berlin, Heidelberg: Springer Berlin Heidelberg; 2014. p. 99-116.

22. Ofengeim D, Giagtzoglou N, Huh D, Zou C, Yuan J. Single-cell RNA sequencing: unraveling the Brain one cell at a time. Trends Mol Med. 2017; 23(6):563-76. https://doi.org/10.1016/j.molmed.2017.04.006.

23. Potter SS. Single-cell RNA sequencing for the study of development, physiology and disease. Nat Rev Nephrol. 2018;14(8):479-92. https://doi. org/10.1038/s41581-018-0021-7.

24. Baslan T, Hicks J. Unravelling biology and shifting paradigms in cancer with single-cell sequencing. Nat Rev Cancer. 2017;17(9):557-69. https://doi.org/1 $0.1038 /$ nrc. 2017.58

25. Cardoso F, Veer LVT, Rutgers E, Loi S, Piccart-Gebhart MJ. Clinical application of the 70-gene profile: the MINDACT trial. J Clin Oncol. 2008;26(5):729-35. https://doi.org/10.1200/JCO.2007.14.3222.

26. Chung W, Eum HH, Lee H-O, Lee K-M, Lee H-B, Kim K-T, et al. Single-cell RNA-seq enables comprehensive tumour and immune cell profiling in primary breast cancer. Nat Commun. 2017:8(1):15081. https://doi.org/10.103 8/ncomms15081.

27. Cabili MN, Trapnell C, Goff L, Koziol M, Tazon-Vega B, Regev A, et al. Integrative annotation of human large intergenic noncoding RNAs reveals global properties and specific subclasses. Genes Dev. 2011;25(18):1915-27. https://doi.org/10.1101/gad.17446611.

28. Tano K, Akimitsu N. Long non-coding RNAs in cancer progression. Front Genet. 2012;3:219.

29. Silva JM, Boczek NJ, Berres MW, Ma X, Smith DI. LSINCT5 is over expressed in breast and ovarian cancer and affects cellular proliferation. RNA Biol. 2011;8(3):496-505. https://doi.org/10.4161/rna.8.3.14800.

30. Zhou W, Ye XL, Xu J, Cao MG, Fang ZY, Li LY, et al. The IncRNA H19 mediates breast cancer cell plasticity during EMT and MET plasticity by differentially sponging miR-200b/c and let-7b. Sci Signal. 2017;10(483): aak9557.

31. Cooper C, Guo J, Yan Y, Chooniedass-Kothari S, Hube F, Hamedani MK, et al. Increasing the relative expression of endogenous non-coding steroid receptor RNA activator (SRA) in human breast cancer cells using modified oligonucleotides. Nucleic Acids Res. 2009;37(13):4518-31. https://doi.org/1 0.1093/nar/gkp441.

32. Askarian-Amiri ME, Crawford J, French JD, Smart CE, Smith MA, Clark MB, et al. SNORD-host RNA Zfas1 is a regulator of mammary development and a potential marker for breast cancer. RNA (New York, NY). 2011;17(5):878-91.

33. Barrett T, Wilhite SE, Ledoux P, Evangelista C, Kim IF, Tomashevsky M, et al. NCBI GEO: archive for functional genomics data sets--update. Nucleic Acids Res. 2013;41(Database issue):D991-5. https://doi.org/10.1093/nar/gks1193.

34. Harrow J, Frankish A, Gonzalez JM, Tapanari E, Diekhans M, Kokocinski F, et al. GENCODE: the reference human genome annotation for the ENCODE project. Genome Res. 2012;22(9):1760-74. https://doi.org/10.1101/gr.135350.111.

35. Krijthe JH: Rtsne: T-distributed stochastic neighbor embedding using Barnes-Hut implementation. R package version 013, 2015. https://github. com/jkrijthe/Rtsne.

36. Hazelton ML, Cox MP. Bandwidth selection for kernel log-density estimation Comput Stat Data Anal. 2016;103:56-67. https://doi.org/10.1016/j.csda.2016. 05.003 .

37. Hänzelmann S, Castelo R, Guinney J. GSVA: gene set variation analysis for microarray and RNA-seq data. BMC Bioinformatics. 2013;14(1):7. https://doi. org/10.1186/1471-2105-14-7.

38. Gendoo DM, Ratanasirigulchai N, Schröder MS, Paré L, Parker JS, Prat A, et al. Genefu: an R/Bioconductor package for computation of gene expression-based signatures in breast cancer. Bioinformatics (Oxford, England). 2016;32(7):1097-9.

39. Andrews TS, Hemberg M. M3Drop: dropout-based feature selection for scRNASeq. Bioinformatics. 2018;35(16):2865-7.

40. Gaujoux $\mathrm{R}$, Seoighe C. A flexible R package for nonnegative matrix factorization. BMC Bioinformatics. 2010;11(1):367. https://doi.org/10.1186/14 71-2105-11-367.

41. Kiselev VY, Kirschner K, Schaub MT, Andrews T, Hemberg M. SC3: consensus clustering of single-cell RNA-seq data. Nat Methods. 2017;14(5):483-6. https://doi.org/10.1038/nmeth.4236.

42. Wang B, Ramazzotti D, De Sano L, Zhu J, Pierson E, Batzoglou S. SIMLR: a tool for large-scale genomic analyses by multi-kernel learning. PROTEOMICS 2018;18(2):1700232. https://doi.org/10.1002/pmic.201700232.

43. Grün D, Muraro MJ, Boisset J-C, Wiebrands K, Lyubimova A, Dharmadhikari $G$, et al. De novo prediction of stem cell identity using single-cell transcriptome data. Cell Stem Cell. 2016;19(2):266-77. https://doi.org/10.101 6/j.stem.2016.05.010.

44. Stuart T, Butler A, Hoffman P, Hafemeister C, Papalexi E, Mauck WM 3rd, et al. Comprehensive Integration of Single-Cell Data. Cell. 2019;177(7):18881902.e1821.

45. Liu B, Li C, Li Z, Wang D, Ren X, Zhang Z. An entropy-based metric for assessing the purity of single cell populations. Nat Commun. 2020;11(1): 3155. https://doi.org/10.1038/s41467-020-16904-3.

46. Lun AT, McCarthy DJ, Marioni JC. A step-by-step workflow for low-level analysis of single-cell RNA-seq data with Bioconductor. F1000Research. 2016:5:2122.

47. Yu G, Wang L-G, Han Y, He Q-Y. clusterProfiler: an R package for comparing biological themes among gene clusters. Omics. 2012;16(5):284-7. https:// doi.org/10.1089/omi.2011.0118.

48. Harmouche-Karaki M, Mahfouz M, Obeyd J, Salameh P, Mahfouz Y, Helou K. Development and validation of a quantitative food frequency questionnaire 
to assess dietary intake among Lebanese adults. Nutr J. 2020;19(1):65. https://doi.org/10.1186/s12937-020-00581-5.

49. Wishart DS, Knox C, Guo AC, Shrivastava S, Hassanali M, Stothard P, et al. DrugBank: a comprehensive resource for in silico drug discovery and exploration. Nucleic Acids Res. 2006;34(suppl_1):D668-72.

50. Wang Y, Zhang S, Li F, Zhou Y, Zhang Y, Wang Z, et al. Therapeutic target database 2020: enriched resource for facilitating research and early development of targeted therapeutics. Nucleic Acids Res. 2020;48(D1): D1031-d1041. https://doi.org/10.1093/nar/gkz981.

51. Corsello SM, Bittker JA, Liu Z, Gould J, McCarren P, Hirschman JE, et al. The drug repurposing hub: a next-generation drug library and information resource. Nat Med. 2017;23(4):405-8. https://doi.org/10.1038/nm.4306.

52. Cheang MC, Chia SK, Voduc D, Gao D, Leung S, Snider J, et al. Ki67 index, HER2 status, and prognosis of patients with luminal B breast cancer. J Natl Cancer Inst. 2009;101(10):736-50. https://doi.org/10.1093/jnci/djp082.

53. Laka K, Makgoo L, Mbita Z. Survivin Splice Variants in Arsenic Trioxide $\left(\mathrm{As}_{2} \mathrm{O}_{3}\right)$-Induced Deactivation of PI3K and MAPK Cell Signalling Pathways in MCF-7 Cells. Genes. 2019;10(1):41.

54. Guo S, Jian L, Tao K, Chen C, Yu H, Liu S. Novel breast-specific long noncoding RNA LINC00993 acts as a tumor suppressor in triple-negative breast Cancer. Front Oncol. 2019:9:1325. https://doi.org/10.3389/fonc.2019.01325.

55. Collette J, Le Bourhis X, Adriaenssens E. Regulation of human breast Cancer by the long non-coding RNA H19. Int J Mol Sci. 2017;18(11):2319. https:// doi.org/10.3390/ijms18112319.

56. Sun Z, Zhang C, Wang T, Shi P, Tian X, Guo Y. Correlation between long non-coding RNAs (IncRNAs) H19 expression and trastuzumab resistance in breast cancer. J Cancer Res Ther. 2019;15(4):933-40.

57. Gao H, Hao G, Sun Y, Li L, Wang Y. Long noncoding RNA H19 mediated the chemosensitivity of breast cancer cells via Wnt pathway and EMT process. Onco Targets Ther. 2018;11:8001-12. https://doi.org/10.2147/OTT.S172379.

58. Shima H, Kida K, Adachi S, Yamada A, Sugae S, Narui K, et al. Lnc RNA H19 is associated with poor prognosis in breast cancer patients and promotes cancer stemness. Breast Cancer Res Treat. 2018;170(3):507-16. https://doi. org/10.1007/s10549-018-4793-z

59. Liang WH, Li N, Yuan ZQ, Qian XL, Wang ZH. DSCAM-AS1 promotes tumor growth of breast cancer by reducing miR-204-5p and up-regulating RRM2. Mol Carcinog. 2019;58(4):461-73. https://doi.org/10.1002/mc.22941.

60. Zheng S, Li M, Miao K, Xu H. SNHG1 contributes to proliferation and invasion by regulating miR-382 in breast cancer. Cancer Manag Res. 2019; 11:5589-98. https://doi.org/10.2147/CMAR.S198624.

61. Pei $X$, Wang $X$, Li H. LncRNA SNHG1 regulates the differentiation of Treg cells and affects the immune escape of breast cancer via regulating miR448/LDO. Int J Biol Macromol. 2018;1 18(Pt A):24-30. https://doi.org/10.1016/j. ijbiomac.2018.06.033.

62. Josephs SF, Ichim TE, Prince SM, Kesari S, Marincola FM, Escobedo AR, et al. Unleashing endogenous TNF-alpha as a cancer immunotherapeutic. J Transl Med. 2018;16(1):242. https://doi.org/10.1186/s12967-018-1611-7.

63. Biswas SK, Mantovani A. Macrophage plasticity and interaction with lymphocyte subsets: cancer as a paradigm. Nat Immunol. 2010;11(10):88996. https://doi.org/10.1038/ni.1937.

64. Carswell EA, Old L, Kassel RL, Green S, Fiore N, Williamson B. An endotoxininduced serum factor that causes necrosis of tumors. Proc Natl Acad Sci U S A. 1975;72(9):3666-70. https://doi.org/10.1073/pnas.72.9.3666.

65. Cruceriu D, Baldasici O, Balacescu O, Berindan-Neagoe I. The dual role of tumor necrosis factor-alpha (TNF-a) in breast cancer: molecular insights and therapeutic approaches. Cell Oncol (Dordrecht). 2020;43(1):1-18. https://doi. org/10.1007/s13402-019-00489-1.

66. Yu M, Zhou X, Niu L, Lin G, Huang J, Zhou W, et al. Targeting transmembrane TNF-a suppresses breast cancer growth. Cancer Res. 2013; 73(13):4061-74. https://doi.org/10.1158/0008-5472.CAN-12-3946.

67. Hagemann T, Wilson J, Kulbe H, Li NF, Leinster DA, Charles K, et al. Macrophages induce invasiveness of epithelial cancer cells via NF-kappa B and JNK. J Immunol (Baltimore, Md : 1950). 2005;175(2):1197-205.

68. Liekens S, De Clercq E, Neyts J. Angiogenesis: regulators and clinical applications. Biochem Pharmacol. 2001;61(3):253-70. https://doi.org/10.1016/ S0006-2952(00)00529-3.

69. Bjørnland K, Bratland A, Rugnes E, Pettersen S, Johansen HT, Aasen AO, et al. Expression of matrix metalloproteinases and the metastasisassociated gene S100A4 in human neuroblastoma and primitive neuroectodermal tumor cells. J Pediatr Surg. 2001;36(7):1040-4. https:// doi.org/10.1053/jpsu.2001.24735.
70. Wang G, Nikolovska-Coleska Z, Yang CY, Wang R, Tang G, Guo J, et al. Structure-based design of potent small-molecule inhibitors of anti-apoptotic Bcl-2 proteins. J Med Chem. 2006;49(21):6139-42. https://doi.org/10.1021/ jm060460o.

71. Squires H, Pandor A, Thokala P, Stevens JW, Kaltenthaler E, Clowes M, et al. Pertuzumab for the neoadjuvant treatment of early-stage HER2-positive breast Cancer: an evidence review group perspective of a NICE single technology appraisal. PharmacoEconomics. 2018;36(1):29-38. https://doi. org/10.1007/s40273-017-0556-7.

72. Nooshinfar E, Safaroghli-Azar A, Bashash D, Akbari ME. Melatonin, an inhibitory agent in breast cancer. Breast cancer (Tokyo, Japan). 2017;24(1): $42-51$.

\section{Publisher's Note}

Springer Nature remains neutral with regard to jurisdictional claims in published maps and institutional affiliations.

\section{Ready to submit your research? Choose BMC and benefit from:}

- fast, convenient online submission

- thorough peer review by experienced researchers in your field

- rapid publication on acceptance

- support for research data, including large and complex data types

- gold Open Access which fosters wider collaboration and increased citations

- maximum visibility for your research: over $100 \mathrm{M}$ website views per year

At BMC, research is always in progress.

Learn more biomedcentral.com/submissions 